\section{British academic morale and pay}

SIR - In his letter on "Action on academic pay" (Nature 356, 10; 1992) Howard Morris demands that the Committee of Vice-Chancellors and Principals (CVCP) "call for a pay review body for university academic and related staff".

The CVCP has long been in favour of a pay review body and has been campaigning for its establishment since early 1990. The debate in the House of Commons as recently as 3 March showed that the government's long-standing determination to resist this idea continues.

DAVID HARRISON

(Chairman)

Committee of Vice-Chancellors

and Principals,

29 Tavistock Square,

London WC1H 9EZ, UK

SIR - In its current evaluation of university and polytechnic departments, the Universities Funding Council (UFC) commits a serious methodological error in attempting to judge research performance by, among other means, the amount of grant income a department is able to attract. The UFC argues that, because the award of a grant is based on independent peer review, the size of a department's grant income reflects the valuation placed on its research plans by the wider academic community.

This choice of yardstick conflicts directly with the UFC's aim, which is "to ensure that resources for research are used to the best advantage". To assess cost-effectiveness, a performance indicator is required that measures number of units of output (for example publications) per unit of input (for example income). Clearly, grant income is not a performance indicator. It is an input measure. As a consequence, the use of grant income to assess performance inevitably produces gross anomalies of measurement.

Suppose that two departments, A and $B$, produce publications of identical quality and quantity over a given period. Suppose also that $\mathrm{A}$ receives twice as much research-grant income as $B$, this being the only difference in their funding. If grant income is used as a performance indicator, then the department with more grant income will be rated more highly. However, in terms of the goal of identifying cost-effectiveness, it is obvious that the reverse is true. The department with less grant income should be rated more highly, having produced the same volume of research with fewer resources.

The inappropriateness of using an input measure as a performance indicator is further highlighted by the fact that a department with an outstanding record of research in areas that require little or no external funding would receive a zero rating, whereas a department with many grants would gain a high rating even if it produced no output at all.

Unlike journal peer review, which critically assesses the merit of a finished product, grant-agency peer review can only make a guess about the promise of future work. To claim that the expert opinion of grant-agency assessors in itself constitutes a judgement of value for money is to beg the question entirely. been obtained can be discovered only by looking at a department's real outputs (not conjectured ones) in relation to its inputs. As per capita grant income is not ally incapable of answering this question.

A measure based on grant income necessarily results in a substantial amount of double counting that spuriously inflates the performance of grantrich departments. The same piece of work can receive two-fold credit, first as anticipated output in a research proposal (measured by grant income) and second as actual output at a later date (measured by number and quality of publications).

The adoption by the UFC of a yardstick based on grant income is clearly antithetical to its objective of obtaining value for money. The continued use of income to measure performance leads inexorably to a situation in which inefficient departments are rewarded and cost-effective departments are penalized.

Department of Psychology, RaphaEl Gillett

University of Leicester,

Leicester LE1 7RH, UK

SIR - Howard Morris draws attention to successive failures by the Committee of Vice-Chancellors and Principals (CVCP) to protect the pay and morale of academic staff in British universities. It is clear that the CVCP has been tested and found wanting in this respect and must be considered no longer fit to negotiate on academic pay.

But let us not forget the role of the government in this sorry saga. In December 1990 , through my MP, I raised specifically the issue of recruitment of scientists into research careers with the Secretary of State for Education and Science, $\mathrm{Mr}$ Kenneth Clarke. In response to my complaints about the difficulty of attracting young people into science at the postdoctoral, postgraduate or even undergraduate level, Clarke's reply was that he could not agree with my premises and he quoted figures sugWhether value for money has indeed a performance indicator, it is structur- gesting that more people rather than fewer were choosing science as a career. Clearly this is not the present experience of those involved in scientific research and training in the United Kingdom.

With a General Election now imminent it is worth recalling that, unlike vice-chancellors and principals, Ministers of Education and Science are voted into office and can occasionally be held to account for at least some of their actions.

\section{Department of Cellular}

M. J. Clemens

\& Molecular Sciences,

St George's Hospital Medical School, London SW17 ORE, UK

SIR - As a former parliamentary candidate and a former nuclear structure researcher, I should like to point out two issues of science administration that must be tackled during the next parliament.

One is the division between 'big' science and 'little' science. It is not sensible that the same institution should be responsible both for funding such large expenditures as the UK subscription to CERN and other international collaborations and for funding research studentships and the many small experiments carried out in university departments. The budget of the Science and Engineering Council (SERC) is unnaturally inflated by 'big' science, which makes considered decisions by politicians and by SERC itself almost impossible to make. Last year's decision by SERC to impose a 10 per cent acrossthe-board cut on all panels smells of dereliction of duty. The CERN subscription in particular should be separately accounted.

The other issue is the coming block obsolescence among UK university staff. Because of the rapid expansion of university education in the $1960 \mathrm{~s}$, a high proportion of academics now in tenured posts were appointed within a few years of each other and will retire within a few years of each other in the early part of the next millennium. Scientists of firstclass abilities who had the misfortune to be born in the late 1940 s or early 1950 s have found it very difficult to continue in fundamental research. Science's loss might have been industry's gain, but there is little evidence that British industry has taken advantage of this windfall. During the next parliament, arrangements should be made, possibly by the use of temporary teaching posts of between 5 and 15 years duration, to spread the period over which the next generation of university teaching (and perhaps a few full-time researchers?) is recruited.

2 Field Close, Bassett Green, DAVE PERKIN Southampton SO2 3DY, UK 